\title{
El efecto de los antioxidantes en mujeres embarazadas con alto riesgo de preeclampsia
}

\author{
Effect of antioxidants on the occurrence of pre-eclampsia in women at increased risk: a randomised trial. \\ Chappell L, Seed P, Briley A y col. The Lancet 1999; 354: 810-15.
}

\section{Objetivo}

Evaluar el efecto del suplemento con vitaminas C y E en mujeres con alto riesgo de preeclampsia.

Primario: comparar el efecto del suplemento con Vitaminas C y E vs. Placebo, sobre marcadores bioquímicos de activación vascular endotelial e insuficiencia placentaria en mujeres con alto riesgo de preeclampsia. Secundario: evaluar el efecto de los antioxidantes sobre la ocurrencia de preeclampsia.

\section{Diseño \\ Ensayo clínico controlado y aleatorizado.}

\section{Lugar}

St. Thomas ' Hospital y Chelsea and Westminster Hospital, Londres, Gran Bretaña.

\section{Pacientes}

Se identificaron 283 pacientes de alto riesgo para desarrollar preeclampsia, basándose en dos estudios de velocimetría Doppler de arterias uterinas anormales, efectuados a las 18 y 22 semanas de gestación; o en presentar historia previa de preeclampsia.

\section{Intervención}

Vitamina C (1000 mg/día) y vitamina E (400 UI/día), desde la aleatorización de las pacientes hasta el parto.

\begin{abstract}
Medición de resultados principales
Se evaluaron resultados clínicos y bioquímicos (el estudio se diseñó principalmente para evaluar estos últimos). Los clínicos incluyeron incidencia de preeclampsia en ambos grupos. Los bioquímicos incluyeron el cociente PAI 1/ PAI 2 (PAI: Inhibidor del Activador del Plasminógeno). Los marcadores plasmáticos de activación endotelial (PAI 1) y disfunción placentaria (PAI 2), fueron medidos mensualmente hasta el parto.
\end{abstract}

\section{Resultados principales}

El análisis fue por intención de tratar. * Un $8 \%$ de las pacientes que fueron asignadas a suplemento con antioxidantes desarrollaron preeclampsia (11/141), mientras que la desarrolló el 17\% (24/142) del grupo placebo $\left(0 R^{*} 0.39\right.$, IC95 0.17-0.90, $\left.p=0.02\right)$. La diferencia entre los grupos fue algo mayor cuando se analizó sólo a la cohorte que completó el estudio. El grupo tratamiento se asoció con una reducción media a lo largo de la gestación del $21 \%$ del Cociente PAI 1 / PAI 2 comparado con el grupo placebo. (IC95 $4-35 \%, p=0.015)$.

\section{Conclusiones}

El suplemento con vitaminas C y E durante la segunda mitad del embarazo en mujeres con alto riesgo de preeclampsia tuvo un efecto beneficioso y significativo sobre los marcadores bioquímicos de la enfermedad. Hubo una reducción significativa en la proporción de mujeres que desarrollaron preeclampsia.

Fuente de financiamiento: Tommy's Campaign y Special Trustees for St. Thomas' Hospital.

\section{COMENTARIO}

La preeclampsia complica entre el 2 y el $8 \%$ de tos embarazos, causa morbi-mortalidad a madres e hijos y produce una elevada demanda de los servicios de salud. A pesar de ello, no existe una estrategia preventiva o que retrase el inicio de la enfermedad. Existe buena evidencia que las mujeres con preeclampsia establecida, tienen un incremento en los derivados de la oxidación lipídica y en el estrés oxidativo de los tejidos deciduo placentarios, así como un mayor consumo de antioxidantes removedores de los radicales libres. Un ensayo clínico controlado aleatòrizado (ECCA) en el cual los antioxidantes se utilizaron para tratar la preeclampsia severa no mostró diferencias significativas en los resultados clínicos. Sin embargo, de iniciar el tratamiento antioxidante, se recomienda hacerlo precozmente para prevenir o retardar la aparición de preeclampsia.

El estudio resumido presenta algunos puntos que hacen que haya que tomar "con reservas" sus conclusiones: a ) Existieron algunas diferencias basales entre los grupos al comenzar el estudio (en cuanto a tabaquismo y origen étnico), que intentaron ser "corregidas" en el análisis multivariable; ${ }^{*}$ b) El estudio fue planeado para demostrar diferencias en los marcadores bioquímicos; y el hallazgo de un efecto clínico beneficioso fue algo inesperado o imprevisto; c) hubo una alta tasa de abandono, cerca del $40 \%$.

Lo que se podría concluir del mismo es que la administración de antioxidantes mejora el perfil bioquímico de estas mujeres. Si bien los resultados muestran una reducción significativa de preeclampsia con la administración de antioxidantes, la elevada tasa de abandono hace que la conclusión pueda no ser la verdadera.

Incluso si fuera probada la eficacia de los antioxidantes en estudios más sólidos habría que disponer de recursos tecnológicos de alto costo, y de personal capacitado para efectuar Eco-Doppler a todas las pacientes a las 18 y 22 semanas como forma de tamizaje. Esto debería ser evaluado en detalle, antes de tomar una decisión que afecte el manejo clínico de la preeclampsia (en particular en países con escasos recursos).

En virtud de la evidencia existente, para la práctica clínica, no se debe recomendar esta intervención hasta no desarrollar estudios adecuados que demuestren eficacia para disminuir la incidencia de preeclampsia con el uso precoz de antioxidantes en pacientes con alto riesgo. El estudio ideal debería dilucidar también el tiempo de administración, la dosis óptima y el efecto a largo plazo en los niños.

*Ver glosario

\section{Dr. Ariel Karolinski}

División Tocoginecología. Htal. Gral. de Agudos Carlos G. Durand. LINERH-CONICET

\section{Referencias}

1. The role of lipid oxidation and oxidative lipid derivatives in the development of preeclampsia. Henriksen T. Semin Perinatol 2000; 24:29-32.

2. Pre-eclampsia associated with increased lipid peroxidation and decreased serum vitamin E levels. Yanik FF, Amanvermez R, Yanik A, Celic C, Kokcu A. Int J Gynaecol 0bstet 19g9; 64: $27-33$. 3. Radical-scavenging antioxidants in pre-eclampsia and eclampsia. Shaarawy M, Aref A, Salem ME, Sheiba M. Int J Gynaecol 0bstet 1998; 60: 123-8.

4. Antioxidants in the treatment of severe pre-eclampsia: an explanatory randomised controlled trial. Gulmezoglu AM, Hofmeyr GJ, 0osthuisen MM. Br J Obstet Gynaecol 1997 ; $104: 689-96$.

5. Magpie: Sulfato de Magnesio para la prevención de la eclampsia. Protocolo de ICCA Multicéntrica Internacional en ejecución. Centro Coordinador Mundial: Institute of Health, Oxford, UK. Investigadora Principal: Lelia Duley. 